\title{
A measurement model for managing performance of horizontal business networks and a research case
}

\author{
Franciele Bonatto ${ }^{\mathrm{a} *}$, Luis Mauricio Martins Resende ${ }^{\mathrm{a}}$, Joseane Pontes ${ }^{\mathrm{a}}$, Pedro Paulo de Andrade Junior ${ }^{\mathrm{b}}$ \\ aUniversidade Tecnológica Federal do Paraná, Ponta Grossa, PR, Brasil \\ bUniversidade Federal de Santa Catarina, Joinvile, SC, Brasil \\ *fbonatto@utfpr.edu.br
}

\begin{abstract}
A significant challenge facing companies that are members of collaborative networks are measuring their market performance, even as they evaluate their contribution to the development of the network. This paper develops a model for analyzing the performance measurement of horizontal business networks. We do this by reviewing literature related to performance management in horizontal networks and systematically selecting eight functional perspectives, and 25 operational factors associated with them, to measure the performance of both companies and the network. We employ the Analytic Hierarchy Process (AHP) for deciding perspective weights and use its quantitative results to create a diagram for representing the effectiveness of performance management at the company and network level. The model is tested by applying it to companies in an Information Technology business network. We analyze the results of the individual and network performance of the companies surveyed, along with the evaluative perspectives relevant to the network.
\end{abstract}

Keywords

Collaborative networks. Performance management. Performance evaluation. Management model. Analytic hierarchy process (AHP).

How to cite this article: Bonatto, F., Resende, L. M. M., Pontes, J., \& Andrade Junior, P. P. (2017). A measurement model for managing performance of horizontal business networks and a research case. Production, 27, e20170051. http://dx.doi. org/10.1590/0103-6513.005117

\section{Introduction}

In recent years, the development of business networks using a collaborative approach has started gaining attention in the world of business as a way for companies to remain competitive in the market (Verdecho et al., 2012; Galdámez et al., 2009; Saiz et al., 2007).

Horizontal networks of companies are defined as complex structures due to simultaneity of cooperation and competition for the business units of companies that are made a part of the network. This relationship is beneficial when businesses work together in pursuit of common goals, even as members retain the power to make own decisions. These organizational models do not necessarily bring competition to an end, but rather allow it to coexist with the cooperation (Neves et al., 2011).

Business networks are organizational arrangements that member organizations can use to initiate, develop, and improve their processes in search of continuous innovation leading to environmental, social, and industrial performance (Diez-Vial, 2011; Delgado et al., 2010). In the last few decades, the structure of enterprise networks has been seen as a tactic for small and medium enterprises (SMEs) to maintain a competitive edge in the market (Verdecho et al., 2012; Galdámez et al., 2009; Saiz et al., 2007).

The companies that are cooperating are focused on achieving peak performance, but they often do not have an efficient framework to structure and manage the performance of a network of companies (Verdecho et al., 2012). 
According to the relevant literature, many factors affecting the collaboration between companies should also be analyzed for any effect they may have on compromising network performance.

In business networks, there is limited knowledge about promoting successful network performance. In the literature consulted for this study, it was observed that one of the biggest difficulties in the management of these networks is the lack of identifiable factors driving network performance, and its measurement. Few studies seek to build models that allow diagnosing these organizational structures, and even more remarkable is the absence of a flexible model that analyzes the performance of horizontal business networks. Another shortcoming highlighted is the absence of a model that allows analysis at both the company and network level, and which would enable the evaluation of the contribution made by members of the network.

This work proposes a model for analyzing performance measurement in horizontal networks of companies, which is capable of assessing both individual and collective performance. For this, eight perspectives and 25 factors covering the performance management in horizontal networks of companies are developed in a systematic way. These perspectives and performance factors are measured through the Analytic Hierarchy Process (AHP), a multi-criteria decision-making method, and equations proposed by the model. Finally, a diagram is generated to support individual and network management, in addition to an individual analysis of the evaluation perspective, to allow benchmarking between the managers.

In the next section, we present the theoretical references to horizontal networks of enterprises, while section 3 covers performance management in horizontal networks of enterprises. On Section 4, the steps for the construction of the model proposed in this work are presented. We apply the model to a network in the Information and Computer Technology (ICT) sector in section 5 and conclude the paper in section 6 .

\section{Horizontal business networks}

Horizontal networks are considered complex business relationships because instances of competition and cooperation among the companies that constitute them may occur simultaneously. The relationships are strengthened when members cooperate in the pursuit of common goals, without inhibiting each other's decision-making power of their members (Neves et al., 2011). Neves et al. (2011) add that, instead of eliminating the competition between members these organizational models sallow it to coexist with their cooperation.

According to Wu et al. (2009), inter-firm relationships in horizontal networks are developed among enterprises in the same productive chain and at a similar level of performance. These networks can also involve other organizations aiding the development of the networks or active in promoting and supporting them

Beugelsdijk et al. (2010), Diez-Vial (2011), and Libaers \& Meyer (2011) state that geographic proximity is a motivational factor for forming regional business networks. These networks are especially beneficial for companies in the same industry, seeking an increase in the competitiveness of their region.

Among the advantages of the geographical proximity of companies, Beugelsdijk et al. (2010) find that new alliances and partnerships emerge withal their aggregation, promoting innovation and more efficient cost control. An increase in collective efficiency, which is the result of joint investments in employee training, and the division of external costs relating to infrastructure, services, labor, and specialized suppliers, makes companies more competitive.

According to Jofre-Monseny (2009), another advantage is the stimulus provided for the improvement of the business network's performance. As the companies belonging to a network are competitors, the competitive pressure created encourages all of them to improve their productivity. It becomes relatively easier for a company to compare itself with another in the network, with the objective of improving its processes and increasing productivity to remain competitive.

It has been observed that geographical concentration, the proximity of member companies, specialization in a product, service, or sector, and a complex balance between cooperation and competition are some of the distinguishing characteristics of horizontal networks of companies.

\section{Performance management in horizontal business networks}

There are several factors affecting the cooperation between companies within the network environment that need to be evaluated to understand any compromise in the network's performance (Verdecho et al., 2012). In these structures, it is hard to find a structured method that provides guidelines for the performance management of 
the network, or one that eliminates the existing friction between the partners, possibly due to a conflict between individual and collective goals (Saiz et al., 2007).

In this context, some studies have attempted to understand this collective relationship, the network's performance management process, the factors that most affect this process, and the performance indicators that can be best adapted to this business structure. The contribution from each study is presented in Table 1 .

Table 1. Contribution of each work raised by systematic review.

\begin{tabular}{|c|c|c|c|}
\hline Author & Perspective & Principle & Characteristics \\
\hline Verdecho et al. (2012) & $\begin{array}{l}\text { Factors and elements } \\
\text { affecting the performance } \\
\text { of companies' networks }\end{array}$ & $\begin{array}{l}\text { Balanced Scorecard system and } \\
\text { Network Analysis Process (ANP) }\end{array}$ & $\begin{array}{l}\text { Developed a structure capable of identifying } \\
\text { the performance measuring factors and } \\
\text { elements that most affect the business } \\
\text { networks' performance }\end{array}$ \\
\hline Saiz et al. (2007) & $\begin{array}{l}\text { Alignment of strategies } \\
\text { between supply chain, } \\
\text { network and company }\end{array}$ & Balanced Scorecard system & $\begin{array}{l}\text { Developed a more complex structure, relating } \\
\text { the individual, chain and network levels to } \\
\text { define a model that can align goals and } \\
\text { strategies in every level }\end{array}$ \\
\hline Francisco et al. (2012) & $\begin{array}{l}\text { Predictive alignment } \\
\text { between network partners }\end{array}$ & $\begin{array}{l}\text { Fit Degree Supporting Tools and } \\
\text { predictive performance measurement }\end{array}$ & $\begin{array}{l}\text { Designed a performance measurement system } \\
\text { to actively assess whether a network partner } \\
\text { is supporting and will continue to support } \\
\text { the network globally so that the strategic } \\
\text { objectives defined by the network can be } \\
\text { realized }\end{array}$ \\
\hline Galdámez et al. (2009) & $\begin{array}{l}\text { Measurement of the } \\
\text { performance in small } \\
\text { and medium companies' } \\
\text { networks }\end{array}$ & Balanced Scorecard system & $\begin{array}{l}\text { Developed an evaluation system for small } \\
\text { and medium business networks to guide the } \\
\text { continuous improvement of these companies, } \\
\text { besides promoting the collaboration and } \\
\text { supporting the decision-making process of } \\
\text { institutions, companies and the other parties } \\
\text { involved }\end{array}$ \\
\hline Pekkola (2013) & $\begin{array}{l}\text { Performance measurement } \\
\text { information }\end{array}$ & Case study & $\begin{array}{l}\text { Examine how different network members } \\
\text { utilize and use network-level performance } \\
\text { measurement information }\end{array}$ \\
\hline
\end{tabular}

$\begin{array}{lll}\text { Francisco et al. (2011) } & \begin{array}{l}\text { Strategic alignment } \\ \text { between partners }\end{array} & \begin{array}{l}\text { Fit Degree Supporting Tools and Key } \\ \text { Alignment Indicators }\end{array}\end{array}$

Measure strategic alignment using indicators due to the different alignment keys and indicators

systems in place for the various participants in a collaborative network

$\begin{array}{lll}\text { Francisco et al. (2010) } & \begin{array}{l}\text { Strategic alignment } \\ \text { between partners }\end{array} & \begin{array}{l}\text { Case studies of two collaboration } \\ \text { networks }\end{array}\end{array}$

Verify that a performance management system helps decision-makers get the alignment between the participants of a collaborative network.

Proposes a method for the design of performance evaluation systems in

Multi-criteria decision support method PROMETHEE, Hierarchical Performance measurement Framework for Performance Analysis template to a network based on individual models of each partner (HFPA), Analytic hierarchy Process Traduisant la REalité) and TOPSIS (AHP), ELECTRE (Elimination Et Choix (Technique for Order Preference by Similarity to ldeal solution)

Methodology of implementation of performance measurement model in collaborative networks

Verdecho et al. (2011)

Implementation and

Ferreira \& Soares (2010)
Analytic Hierarchy Process (AHP) and

Balanced Scorecard system pmColNet. collaborative networks through an innovative combination of performance information classification and multi-criteria decision model. The method is implemented in a webbased collaborative platform that enables the members of a collaborative network to efficiently achieve specific performance models that result from a collective and negotiated construction

Provide a methodology based on the multi-criteria decision method that helps implement the different elements that comprise a performance measurement system for collaborative networks

Describes an approach for the design of performance management models in collaborative networks, from a constructivist approach. 3 organizations implement a model.

Creation and redefinition of performance indicators, guaranteeing a platform that facilitates the efficiency of the strategy established by managers and promotes the strategic alignment between the partners. 
Table 1. Continued...

\begin{tabular}{|c|c|c|c|}
\hline Author & Perspective & Principle & Characteristics \\
\hline Verdecho et al. (2010) & $\begin{array}{l}\text { Selection of suppliers } \\
\text { for sustainable business } \\
\text { networks }\end{array}$ & $\begin{array}{l}\text { Analytic Hierarchy Process (AHP), } \\
\text { Network Analysis Process (ANP) } \\
\text { and three dimensions of supplier } \\
\text { sustainability. }\end{array}$ & $\begin{array}{l}\text { The authors develop a system based } \\
\text { in the performance perspectives and } \\
\text { indicators proposed by the system Balanced } \\
\text { Scorecard, in the three dimensions of } \\
\text { supplier sustainability and in the use of the } \\
\text { network analysis process (ANP), allowing } \\
\text { the connection between the suppliers' } \\
\text { sustainability criteria and the performance } \\
\text { indicators defined by all the collaborating } \\
\text { companies. }\end{array}$ \\
\hline Ferreira et al. (2011a) & $\begin{array}{l}\text { Performance measurement } \\
\text { model for collaborative } \\
\text { networks based on key } \\
\text { factors of success of } \\
\text { stakeholders. }\end{array}$ & Key factors for success & $\begin{array}{l}\text { 1dentifies the main stakeholders and the } \\
\text { most relevant success factors that provide the } \\
\text { perspective for the performance evaluation } \\
\text { and improvement. }\end{array}$ \\
\hline
\end{tabular}

In studies referred to in Table 1, the authors expend great effort to build tools that measure performance in collaborative networks. These networks are seen as complex structures that encompass many factors and indicators that may interfere with the individual development of the partners and the network as a whole.

A key question that most studies try to answer is: how to build a model of evaluation, addressing factors and indicators that measure the performance of these collaborative networks? To build a single model that is capable of measuring the performance of all partners and the network, it is essential to use multi-criteria methods to support decisions that assist in the implementation of different elements that make up a performance measurement model for collaborative networks (Verdecho et al., 2010; 2011; 2012; Ferreira et al., 2011a, 2011b; Francisco et al., 2011; 2012).

For the construction of network models, most authors follow the balanced scorecard (Kaplan \& Norton, 1992) principle. The balanced scorecard methodology uses four perspectives: financial, customer, internal processes, and learning and growth. In previous studies, some authors include a perspective that evaluates the collaboration element in collaborative networks, and focus their efforts on creating appropriate measurement factors and indicators for each perspective. It is worth noting the attempt to adapt the existing collaborative network models; however, the adaptation may not be satisfactory because of the peculiarities of each network, and the usefulness of factors and indicators that are selected for measuring the performance of the network.

Other studies are focused on the alignment of the strategies of the members of the network. To that end, key indicators of alignment are used, in an attempt to develop a framework of indicators using key indicators of success of the member companies of the network. Creating indicators allows one to evaluate the individual contribution of members in the development of the network.

In summary, it is clear that many have attempted to create tools for assessing the performance of these complex structures. However, all these models evaluate the network as a rigid structure, a single entity. This approach presents difficulties in assessing the weaknesses, as well as strengths of the network. Once the network is an articulated structure and the sum of all the constituent companies, it is necessary to evaluate individually each of its parts. By doing this, one can construct a baseline that permits more effective actions, either in the management of individual companies or of the network as a whole. Furthermore, approaching the network as a hinged structure allows the development of models that can be adapted to different productive environments.

This article proposes the development of a model for analyzing individual and collective actions and the performance of each company participating in a horizontal network.

\section{Proposed model}

The proposed model was developed in 5 steps, as shown in Figure 1.

Step 1: Development of a conceptual model

The procedure adopted for the construction of the conceptual model was based on Methodi Ordinatio (Pagani et al., 2015), a methodology which presents criteria to select scientific articles. It consists of 7 phases for the selection and classification of a bibliographic portfolio:

Phase 1 - Establishing the intention of research;

Phase 2 - Preliminary exploratory research focusing on keywords in databases; 


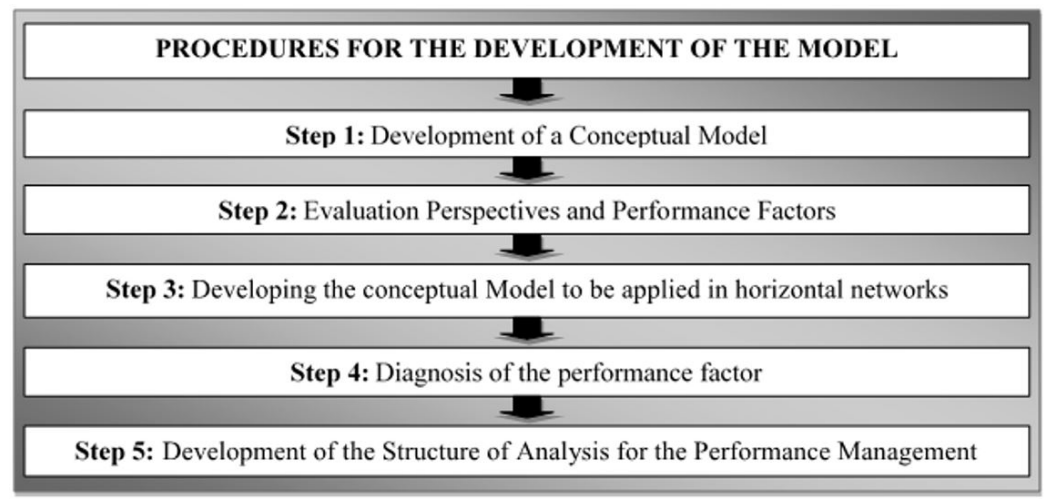

Figure 1. Steps taken to develop the model proposed in this research.

Phase 3 - Definition and combination of keywords and databases;

Phase 4 - Final search in the databases;

Phase 5 - Filtering procedures;

Phase 6 - Identification of impact factor, year of publication, and the number of citations;

Phase 7 - Ranking papers selected by using the lnOrdinatio, after carrying out all the preceding phases.

Following is a description of each phase involved in the selection of the portfolio of articles used in this research.

Phase 1: The objective of the first phase or the research was to select relevant articles in the area of performance management in horizontal networks of companies. This was done to identify the perspectives to be evaluated and factors, associated with each perspective, to be used for the measurement of company and network performance.

Phase 2: A preliminary survey was carried out of the various databases, with the purpose of identifying the most commonly used keywords in the articles containing "performance management" and "collaborative networks."

Phase 3: Fourteen databases were selected for online searches: Cambridge, Emerald, Oxford, IEEE Explore, PNAS Journals, Science Direct, Jstor, Gale, Scopus, SAGE, Springer, Web of Science, Compendex, and Scielo. Then, keywords for each line of research and its word combinations were defined, as shown in Figure 2.

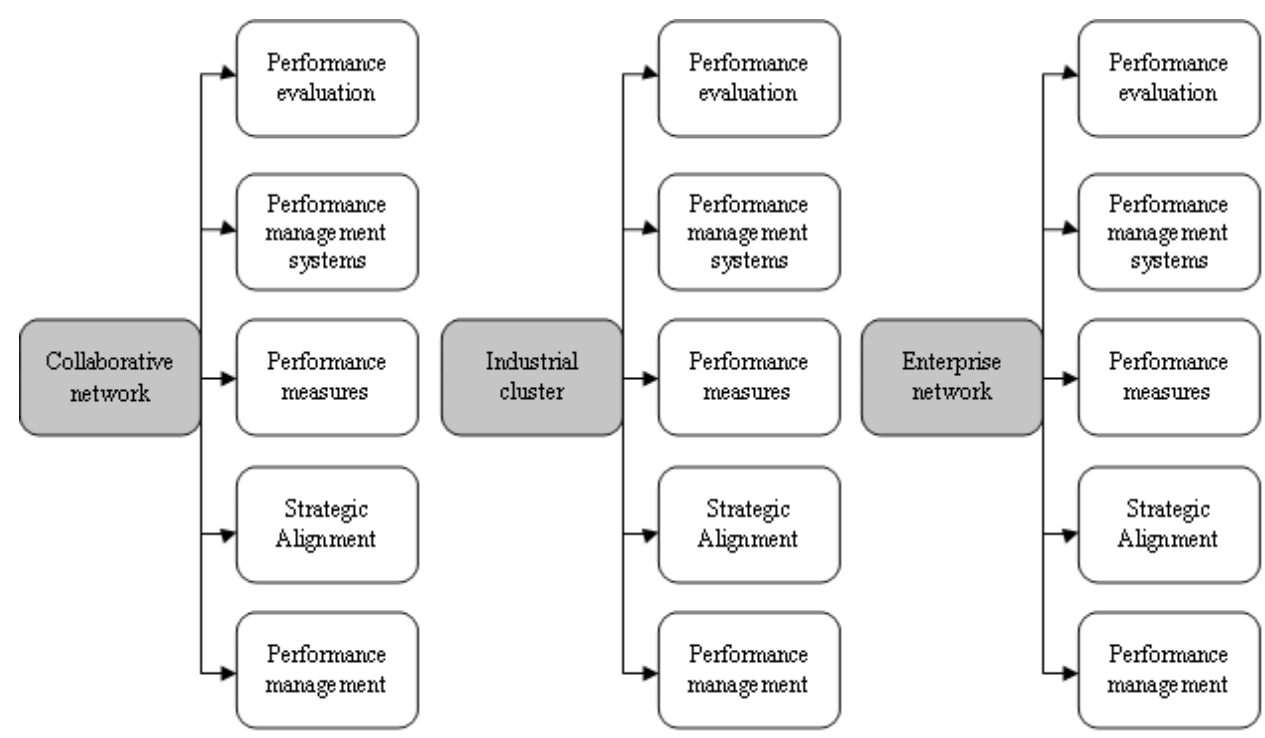

Figure 2. Keyword Combinations. 
Phases 4 and 5: With the definition of the databases and the keyword combinations, we restricted our search to work published between 2003 and 2013, which resulted in the short listing of 192 articles. In order to refine the search, four consecutive steps were undertaken: 1$)$ exclusion of duplicates (121 articles eliminated); 11) reading titles and excluding articles that are not aligned with the research themes ( 3 articles); 111) making arrangements for the availability of the full text (7 articles); IV) full reading of the articles and exclusion of the ones that are not aligned with research objective (1 article).

At the end of the steps, 20 articles were selected. Due to the limited number of relevant articles found, it was not necessary to apply phases 6 and 7 used for ranking proposed by the methodology.

Based on these articles, it was possible to identify the performance perspectives and factors in horizontal business networks

Step 2: Evaluation perspectives and performance factors

From the reading of selected works, two levels of variables were produced. The initial ones are structural variables, herein called perspectives or dimensions. The second type consists of operational variables, herein called factors. Thus, each perspective can consist of one or more factors.

Eight different perspectives emerged from the literature related to the analysis of performance in horizontal business networks, along with 25 factors associated with these perspectives, as shown in Table 2.

Table 2. Performance perspectives and factors for horizontal business networks.

\begin{tabular}{|c|c|}
\hline Perspectives & Performance Factors \\
\hline Economic/Social & $\begin{array}{l}\text { Professional qualification } \\
\text { Regional contribution } \\
\text { Company growth }\end{array}$ \\
\hline Environment & Waste disposal \\
\hline Social Capital & $\begin{array}{l}\text { Company's contribution to cooperative } \\
\text { Actions } \\
\text { Company's contribution to the network }\end{array}$ \\
\hline Financial & $\begin{array}{l}\text { Sales } \\
\text { Profitability } \\
\text { Total cost of the company }\end{array}$ \\
\hline Client & $\begin{array}{l}\text { Clients favorable to the product } \\
\text { Client's loyalty } \\
\text { Complaints/delation }\end{array}$ \\
\hline Process & $\begin{array}{l}\text { Non-conformities } \\
\text { Variation of the production's lead time } \\
\text { Alignment of procedures and methods } \\
\text { lnitiatives for performance improvement } \\
\text { Delivery terms } \\
\text { Stock control }\end{array}$ \\
\hline Growth/Learning & $\begin{array}{l}\text { Forecast of market changes } \\
\text { Innovative products } \\
\text { Courses, trainings, lectures }\end{array}$ \\
\hline Collaboration & $\begin{array}{l}\text { Collaborative meetings between partners } \\
\text { Health of collaboration index } \\
\text { Collaborative practices among partners } \\
\text { Quantity and quality of the information }\end{array}$ \\
\hline
\end{tabular}

The economic/social perspective is used to measure the positive effect on the local and regional economy by the creation of a collaborative network. The main factors that affect performance in this dimension are: professional qualification, regional contribution, and company growth (Galdámez et al., 2009)

In regard to the inclusion of the environmental perspective in performance evaluation system for enterprise networks, Galdámez et al. (2009) remark that the environment perspective analyzes the environmental impact of the production system of companies constituting the horizontal network. Within this dimension, waste disposal is the factor analyzes the appropriate destination of the waste generated by the production process of the company and the performance of related actions, such as recycling, waste reuse, and the reprocessing of waste products.

The social capital perspective is used to evaluate the level of cooperation between the companies incorporated in the network, the contribution of businesses to the development of the network, and the advantages obtained by the participating companies in coming together (Galdámez et al., 2009; Xu et al., 2011). Coleman (1988) defines social capital by its function, considering it as a variety of resources which share aspects of their social structure in order to facilitate certain actions of the social actors (people or groups). Like the other kinds of capital, social 
capital is productive, allowing kind of actions that would not be possible in its absence. Coleman (1988) highlights the different groups work together and the reciprocity and degree of confidence in the relationships established among them.

The financial perspective is often critical in deciding whether it is advantageous to join a business network. In fact, if a company demonstrates unsatisfactory financial results after its inclusion in the network, it indicates failures in the creation and development of its structure (Saiz et al., 2007; Verdecho et al., 2010; 2011; Lima et al., 2011; Xu et al., 2011). The client's perspective provides managers with incentives to identify the target customers and the market segments, in addition to an assessment of each firm's performance (Saiz et al., 2007; Verdecho et al., 2010; 2011).

The process perspective, from the point of view of the customer, is understood as a result of performance delivery and quality of the products offered to the customers. Customers expect their orders to be delivered at the agreed time and without any nonconformity or defect, and are not concerned with the efficiency of operations and the costs involved (Saiz et al., 2007; Verdecho et al., 2010; 2011; Lima et al., 2011; Galdámez et al., 2009).

The learning and growth perspective is used to measure the infrastructure to be built by the organization to create long-term improvement (Saiz et al., 2007; Verdecho et al., 2010; 2011).

The collaboration perspective refers to the perception of each member on the quality of interaction between firms within the network. Information and knowledge sharing has a direct impact on how firms cooperate and manage the network and its operations (Verdecho et al., 2011; Lima et al., 2011; Xu et al., 2011; Galdámez et al., 2009).

Once the perspectives and performance factors were defined, it was necessary to develop a model that would measure them.

Step 3: Developing the conceptual model to be applied in horizontal networks

After defining the eight perspectives, we decided to rank these perspectives according to their relevance/importance in the network to be studied.

For attaching weights to perspectives, we used the AHP (Analytic Hierarchy Process), a method to support multi-criteria decision-making, developed by Saaty (1990). The choice was supported by the fact that the perspectives were independent of each other and i less than 9 in number. One of the advantages of choosing this method is being able to assess the rate of consistency of responses assigned when considering the alternatives.

By using the AHP method, weights were assigned to perspectives by comparing them with each other in various pairs of perspectives (PSPs). Thus, all the PSPs are analyzed, to record the relative importance of each perspective.

According to Saaty (1990), the judgment on importance is based on the answers to two questions: which element is more important to regards to an upper level criterion in the hierarchy, and what its superiority on a scale ranging from 1-9, in increments of two, is.

Thus, a peer comparison of the elements (PSPs) of the model was performed. These comparison ratings were obtained by directly administering surveys to the individuals involved in the decision-making process. The network's governance structure must perform a comparative evaluation of the weights attached to the model's perspectives.

Next, the ratings obtained were arranged in a NxN matrix. Thereafter, the procedure mentioned in AHP was used to obtain the values representing the weights attached to each of eight perspectives. Afterwards, the consistency rate (CR) for the values attributed to the perspectives was calculated to make the values correspond to reality, or in other words, to get a $C R \leq 0.10$, as per Saaty (1990).

At this stage of analysis, performance factors or indicators, capable of being used for enterprises, as well as for the network), were defined and assigned to the relevant weighted perspective.

Step 4: Diagnosis of the performance factors

To analyze if and how enterprises, as well as the network, manage their performance, it was necessary to investigate the use of indicators by enterprises and by the network.

As the model had to evaluate not only enterprise's performance, but also network's performance, it was necessary to analyze the use of indicators at both these levels.

The use in the individual company level would capture the internal competency of the company. At the network level, the diagnosis would identify those performance indicators that need to be shared with the network for the purpose of promoting the network's development and strength.

To achieve this goal, the respondents were asked whether they had indicators for each of the performance factors, and how they were used. Depending on the incidence of use of indicators in the company and at the network level, a rating was given, as shown in Table 3. 
Table 3. Levels of response in relation to the use of indicators to evaluate each performance factor at individual and network levels.

\begin{tabular}{cl}
\hline & Use of indicators at the company's individual level \\
\hline Answer & \\
\hline 0 & Absent \\
1 & Hescription \\
2 & Has it, but doesn't use it \\
3 & Has it and uses it irregularly \\
4 & Has it and uses as reference for benchmarking \\
\hline Answer & \multicolumn{1}{c}{ Use of indicators at the network level } \\
\hline 0 & Doesn't know and doesn't share it with the network \\
1 & Only receives and/or provide indicators \\
2 & Share indicators \\
3 & Share indicator and work together in the search for goals \\
4 & The network has its own indicators based on the companies' indicators \\
\hline
\end{tabular}

By giving a rating between 0-4 for the response in each of the 25 performance factors, it is possible to quantify the performance of the model. First, we extract the final value for each perspective at the individual company level, by using the ratings for their associated factors, as shown in Equation (1).

$$
V f(P S P)=\left(\sum_{j=1}^{n} R\right) \cdot P
$$

Where:

$\mathrm{Vf}(\mathrm{PSP})=$ Final value of the perspective;

$\mathrm{R}=$ Response for each factor;

$\mathrm{P}=$ Weight of the perspective;

It is important to note that the application of Equation (1) will give us the company level score for each perspective, but only for one company. Therefore, the same procedure must be repeated for all companies analyzed and for all the eight perspectives. The sum of all perspective scores will generate a value for the company's internal performance management, as shown in Equation (2) below.

$$
\mathrm{G} \text { (internal) }=\sum_{j=1}^{n} V f(P S P)
$$

Where:

G (internal) = Company's internal management;

$\mathrm{V} f(\mathrm{PSP})=$ Final value of each perspective.

Using the result obtained in Equation (2), it is possible to identify the current level of the company's internal management in relation to that of the other companies in the network. Calculating the score for the performance in the external or network level also makes use of Equations (1) and (2), but the responses included are those that quantify the use of indicators at the network level.

Therefore, with the application of mathematical operations presented here, it is possible to identify the status of both the individual performance management of the company, and the collective performance management of the network.

\section{Step 5: Development of the structure of analysis for performance management}

To build the diagram, it is first necessary to establish the maximum values for both the individual and network performance management, or in other words, to decide on the range of values on the diagram axes. We designate the horizontal axis, $\mathrm{X}$, as the individual performance management axis, and use the vertical axis $(\mathrm{Y})$ for representing network performance management.

The maximum value for each axis is decided by using Equation (3). The weight assigned to each perspective by using the AHP is multiplied by the number of factors for each perspective and the maximum rating for these factors (4). This product is divided by the sum of weights of evaluation perspectives. 


$$
V M=\frac{\sum_{j=1}^{n} P p s p . N F .4}{\sum_{j=1}^{n} P p s p}
$$

Where:

$\mathrm{VM}$ = Maximum value of the axis;

Ppsp = Weight assigned to the perspective;

$\mathrm{NF}=$ Number of factors per PSP

It is also important to comment that those factors that do not apply to a network are excluded when we calculate the maximum values of the diagram's axes. With the use of these values, we can build the diagram representing the Individual and Network Performance Management effectiveness, as shown in Figure 3.

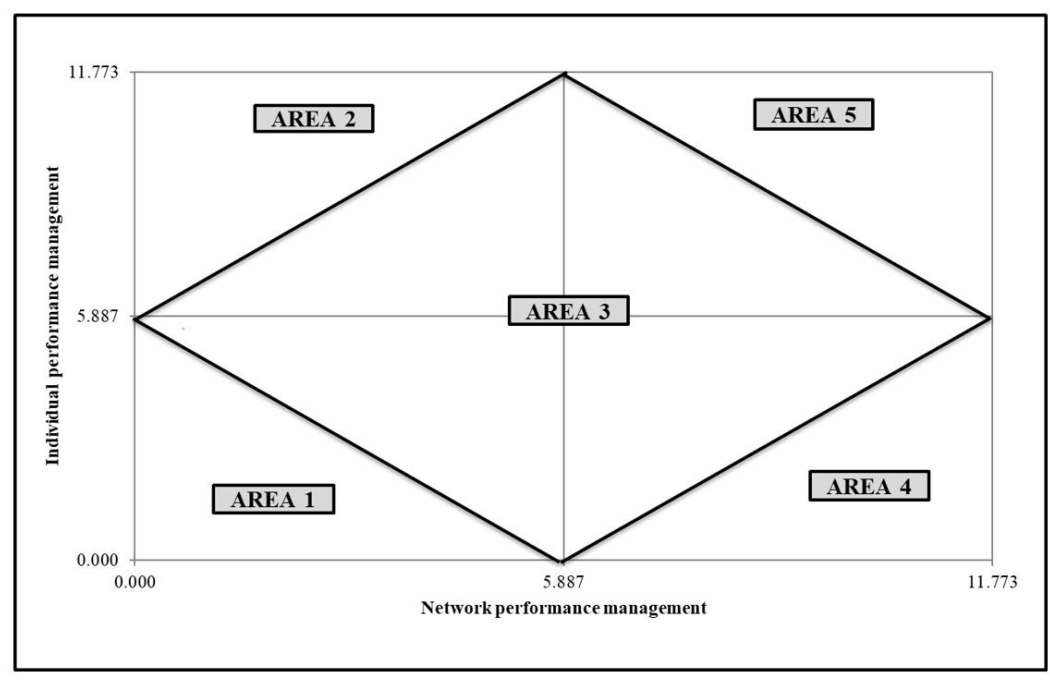

Figure 3. Diagram Individual Performance Management X Network Performance Management.

In order to facilitate the diagram's analysis, it has been divided into five areas: deficient individual and network management (AREA 1); developed individual management and critically deficient network management (AREA 2); transitional individual and network management (AREA 3); deficient individual management and developed network management (AREA 4); optimum individual and network management (AREA 5). Each area of the diagram is described below:

\section{Area 1- Deficient individual and network management}

A position in this area indicates a low and/or null cooperation between the companies within the network in terms of performance evaluation indicators. The companies in this area have neither knowledge about, nor surveillance of their individual performance. The companies have not used indicators to evaluate the main factors that demonstrate the internal performance of the organization and the advantages of integrating with a horizontal business network.

The companies in this area of the diagram and the network's governance team need to ensure that the sharing of performance indicators and information happens between partners, stimulating the cooperation and the development of the companies' individual management.

\section{Area 2 - Developed individual management and deficient network management}

The companies that find themselves in this area off the diagram have the required knowledge to monitor the internal performance of the company with the use of indicators. However, they do not cooperate, by exchanging performance information with partners, which goes against the aims of a business horizontal network.

Companies in this area need to prioritize the improvement of cooperative actions with partners. This can happen by the release of performance indicators and management information, aimed at balancing the individual and the network performance management. 


\section{Area 3 - Transitional individual and network management}

We can assume that companies in this area already exhibit some form of individual performance management control, and some knowledge in the network's performance management also. Networks placed in this area already present some knowledge and performance control, but there are some limitations.

Companies in this area should look for actions to improve the inter-company relationship in order to stimulate the development of a business horizontal network. They also need to develop the company's internal management to be able to use indicators that show the company's main limitations and weaknesses, allowing the indicator values to guide the search for goals.

Companies in this transitional area must also search for the balance of individual and network performance management in order to achieve a balanced development and move to area $\mathrm{V}$ of the diagram.

\section{Area 4 - Critically deficient individual management and developed network management}

This area represents a position where companies have a good inter-company relationship a characteristic of a horizontal business network, but they need to develop their internal management, seeking the use of indicators that can communicate to managers the company's weaknesses and strengths, accelerating the search for goals and improvements.

Although it seems quite irrational to have a strong use of collective indicators and a weak performance in internal indicators, this situation can occur when some enterprises of the network explore possibilities of cooperation in terms of sharing the information and the indicators of external performance but do not develop or use their own indicators. Another possibility is that the network presents its own indicators and some enterprises do not use them in a regular manner, internally. It does not seem likely to have a major concentration of the enterprises of a network in this area, but the presence of a few enterprises is possible

\section{Area 5 - Developed individual and network management}

This area indicates a position best suited for an efficient performance management of a business network. It means that the companies that find themselves in this area have strong internal performance control and use indicators to reach their individual targets.

Companies in this area are also characterized by their compliance with the procedures of horizontal business networks, showing a high level of trust and cooperation between partners. This translates into the communication of performance indicators and information and the joint search for the development goals of the network. Thus, a presence here indicates that the company's internal management is focused on reaching established goals and the business network is consolidated, and even sharing its management system with the entire network.

\section{Application of the model in the horizontal business network of information and communication technology of Ponta Grossa}

The model we developed was applied to the analysis of a horizontal business network of ICT companies, active since 2006 in the central east region of Brazil's Paraná state.

The nucleus of the network currently consists of eleven companies specialized in software development and support area, and they are all located in the city of Ponta Grossa in the east-central region of the state of Paraná.

The horizontal business network studied has support from two local universities and a college, as well as from the City Hall, with whom it has jointly been organizing meetings, coaching, and the selection of employees and trainees. Some enterprises of the network trace their origin to the business incubator in one of the supporting universities.

As stated by the network governance team, its strategy is to improve the number of active companies, in order to enhance actions. The member companies of the network hold weekly meetings weekly to discuss and define actions for their development. These companies also get preferential treatment from the supporting institutions, such as discounts in courses, training programs, etc. They are priority vendors for installations in the local Technological Park.

In the first stage, the applicability of the perspectives and performance factors to the network is verified. This stage was performed in the presence of the network's president. As a result, we decided to remove the environment perspective, and the stock control factor from the model processing perspective. This decision was taken because the companies from the Information Technology sector do not have to deal with a significant level of stock as most of their operations are digitalized. The removal of the Environment perspective was justified as the companies do not generate significant waste in their productive process. Next, we were able to obtain weights for the evaluation of various perspectives. 
At the second stage, a survey was administered to decision makers in the eleven companies selected, with the purpose of assessing the use of indicators to evaluate the performance factors at individual and network levels. Managers who had thorough knowledge in their companies answered the survey. The data collected was processed by using Equations (1) and (2).

The third stage is where the maximum values for the $X$ and $Y$ axis of the diagram were derived using Equation (3). With this, the diagram for the horizontal network studied could be built, as shown in Figure 4.

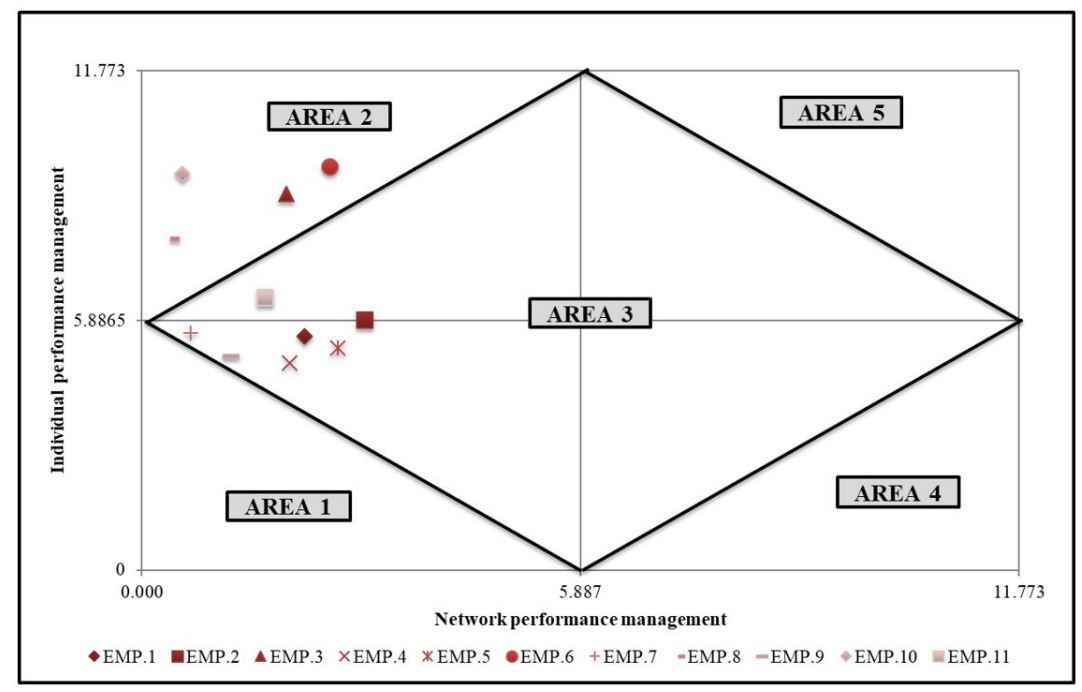

Figure 4. Diagram of Individual X Network performance management of the 1CT of Ponta Grossa. EMP.1: Company 1; EMP.2: Company 2; EMP.3: Company 3; EMP.4: Company 4; EMP.5: Company 5; EMP.6: Company 6; EMP.7: Company 7; EMP.8: Company 8; EMP.9: Company 9; EMP.10: Company 10; EMP.11: Company 11.

After analyzing the performance management of the member companies, four companies (companies 3, 6, 8 and 10) are placed in the area 2 of the diagram; they exhibit a developed individual management process, along with critically deficient network management.

According to the model developed, the companies located in this area have knowledge and monitor the internal performance of the company with the use of indicators. However, the companies practice very little or no exchange of performance information between partners and/or release of indicators between other companies within the network, which goes against the defining characteristic of the horizontal business network.

Companies that find themselves in this area present a structured internal management process, with formalized indicators and, most often, a method to control the search for goals. Companies such as 8 and 10 have shown a tendency of withdrawal from the network, being inactive both in sharing of indicators and participating in actions developed by the network. In the case of companies 3 and 6, even if they present a structured internal management process, there is an exchange of indicators among companies. However, it was clear that only some partners shared indicators in an informal manner.

The seven companies (companies 1, 2, 4, 5, 7, 9, and 11) located in the area 3 of the diagram the transitional internal and network management area have some form of internal management control due to their use of indicators to evaluate performance. This use proved to be informal and, when formally practiced, there was no procedure in place to monitor the targets. These companies also had knowledge in the network performance management, but it was limited to the informal share of indicators between some businesses, there is no formal arrangement for communication among all companies within the network.

Companies in the transition area need to develop their internal management, targeting the use of indicators that can inform managers about the limitations and weaknesses, the company is dealing with, stimulating the application of indicators to guide them to their goals. As for the development of network management, these companies must formalize the performance indicators shared with the other companies, as stated in Francisco et al. (2010; 2011), and Francisco \& Azevedo (2009). 
These companies need to look for a balance between the individual and network management, aiming at a balanced development with the aim of getting to area $\mathrm{V}$ of the diagram.

A relevant fact pointed by the managers was the trust between partners. Regarding the sharing of information and indicators among companies, partners who have mutual trust and who have worked closely together have long shared informally. These results are commented on in Wegner \& Ribeiro (2011), where they pointed out difficulties in evaluating network performance. Entrepreneurs who have spent a long time in the network tend to create bonds of trust and cooperate more, unlike entrepreneurs who are in the network for a short time, and tend to limit their cooperation and the sharing of information, as there is a lack of trust between them (Wang et al., 2014).

Another aspect highlighted is the lack of standards and formalized indicators between enterprises, which makes the interchange of indicators more difficult. Francisco et al. (2010; 2011), attest to difficulties in analyzing performance network when the enterprises do not use standard indicators. In such a case, the authors attest that it is of fundamental importance to use key indicators of performance as a support to evaluate network performance.

Horizontal business networks at different stages of development can present varying levels of performance management. In the literature, networks' development is described, in a generic way, by using phases such as birth, growth, maturity, and decline (Potter \& Watts, 2010; Wegner et al., 2013). A network in its birth phase, or one constituted by managers with weak links between them, tends to show a low level of performance management. This is not a problem when the network is in the development phase as time is necessary to build stronger links and create the conditions for sharing strategic information.

However, a network in a growth or maturity phase with a low level of performance management is a problem, especially if there are other problems or factors that prevent deeper relationships and links to form. These aspects are studied by Wegner \& Ribeiro (2011).

In this context, the business network studied here, formed eleven years ago is in an undesirable situation, given that all the enterprises analyzed are members of the network for more than three years. The low level of network performance management is apprentice enterprises are unable to deepen links of cooperation with each other.

The model also allows the individual evaluation of the perspectives, identifying the areas that need to use indicators to support both the company and network performance measurement.

In regard to the economic/social perspective, Figure 5 illustrates that, internally, companies have used indicators to evaluate such perspectives and they are commonly used to monitor results, informally. However, the network does not use indicators for this perspective and the companies do not share their indicators with other companies.

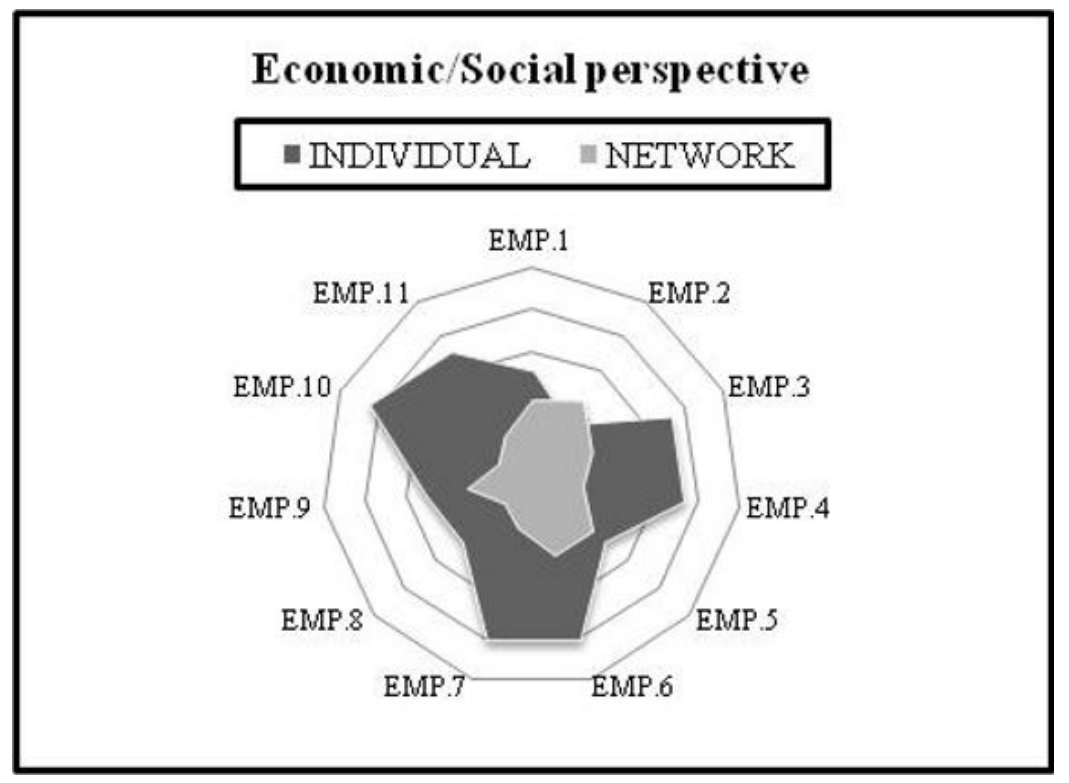

Figure 5. Individual and network management for the Economic/ Social perspective. EMP.1: Company 1; EMP.2: Company 2; EMP.3: Company 3; EMP.4: Company 4; EMP.5: Company 5; EMP.6: Company 6; EMP.7: Company 7; EMP.8: Company 8; EMP.9: Company 9; EMP.10: Company 10; EMP.11: Company 11. 
For the social capital perspective, as illustrated in Figure 6, only companies 2, 3, 6, and 11 make use of indicators. They apply these indicators formally to evaluate the company's contribution to cooperative actions and its contributions to the network. We observed a lack of knowledge about the availability of indicators for this perspective, and, even when indicators were known, their use was informal. At the network level, only companies 2, 3, and 6 receive, provide, or share indicators in a formal manner. The remaining companies only receive information, because they do not apply indicators internally.

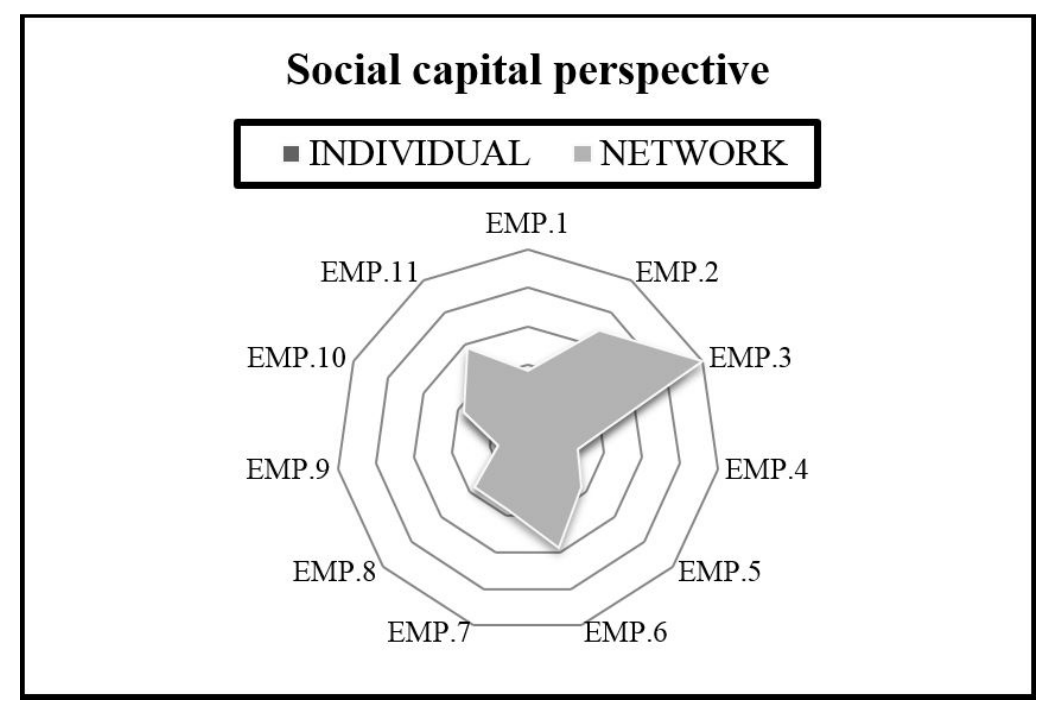

Figure 6. Individual and network management for the Social Capital perspective. EMP.1: Company 1; EMP.2: Company 2; EMP.3: Company 3; EMP.4: Company 4; EMP.5: Company 5; EMP.6: Company 6; EMP.7: Company 7; EMP.8: Company 8; EMP.9: Company 9; EMP.10: Company 10; EMP.11: Company 11.

We conclude that the financial perspective is the most relevant for managers (4.261), followed by the client perspective (2.226), and the economic/social perspective (2.058).

For the financial perspective, according to Figure 7, we observed that all companies have and use formal indicators to evaluate the financial aspects.

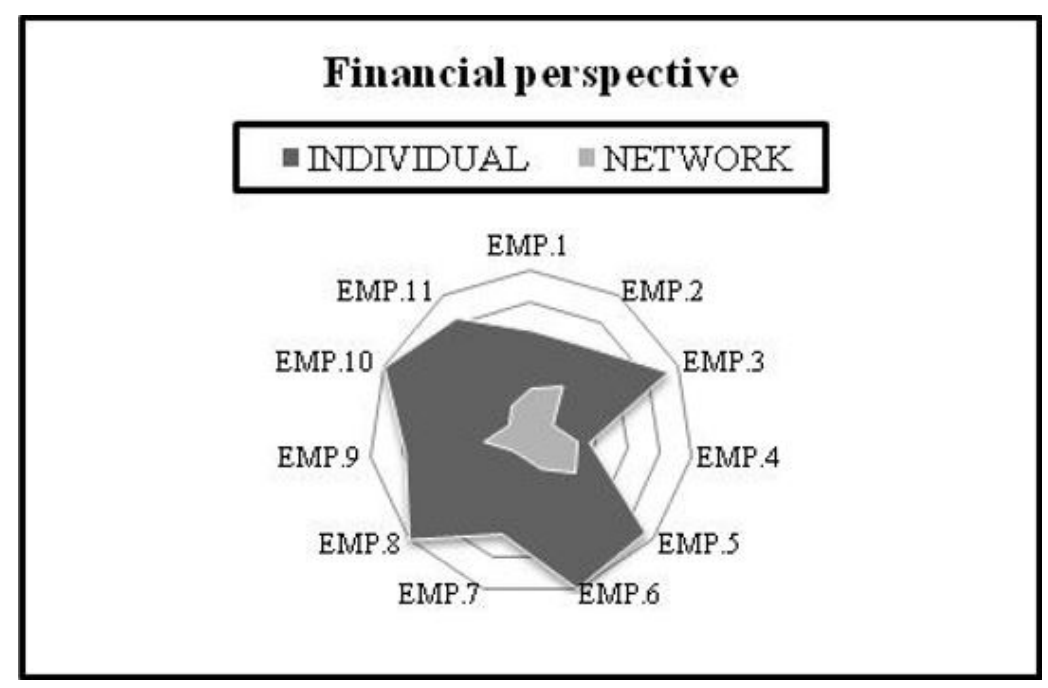

Figure 7. Individual and network management for the Financial perspective. EMP.1: Company 1; EMP.2: Company 2; EMP.3: Company 3; EMP.4: Company 4; EMP.5: Company 5; EMP.6: Company 6; EMP.7: Company 7; EMP.8: Company 8; EMP.9: Company 9; EMP.10: Company 10; EMP.11: Company 11. 
It has been also observed that the companies 3, 5, 6, 8, and 10 use formal indicators and apply them to monitor results. However, there is almost no sharing of these indicators with the network, and when it occurs, it is only between partners considered reliable, and that too in an irregular way.

With regard to the client perspective, Figure 8 demonstrates that the companies have and use the formal indicators, in some cases, to reach targets and evaluate the client aspects. However, these indicators are not shared with the network.

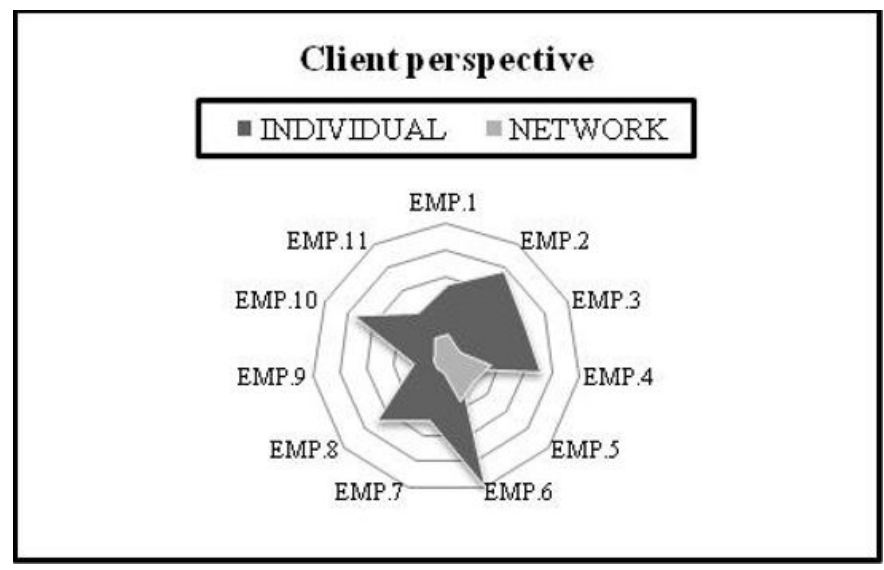

Figure 8. Individual and network management for the Client perspective. EMP.1: Company 1; EMP.2: Company 2;

EMP.3: Company 3; EMP.4: Company 4; EMP.5: Company 5; EMP.6: Company 6; EMP.7: Company 7; EMP.8: Company 8; EMP.9: Company 9; EMP.10: Company 10; EMP.11: Company 11.

Based on interviews with managers, we observed that both the financial and client indicators are not released to the network. The explanation is that such information could not be revealed to their competitors. In other words, the indicators that could benefit their competitors are not be shared with other companies.

As for the process perspective, Figure 9 illustrates that the companies 6, 8, and 10 have and use performance indicators in search for goals and for the factors assigned for the evaluation of the process perspective. In other words, the non-conformities, the variation in the production lead time, the alignment between procedures and methods, the implementation of initiatives for performance improvement, and product delivery terms. For the remaining companies, we observed that these companies have no indicators to evaluate these factors and, when they do, the use is irregular.

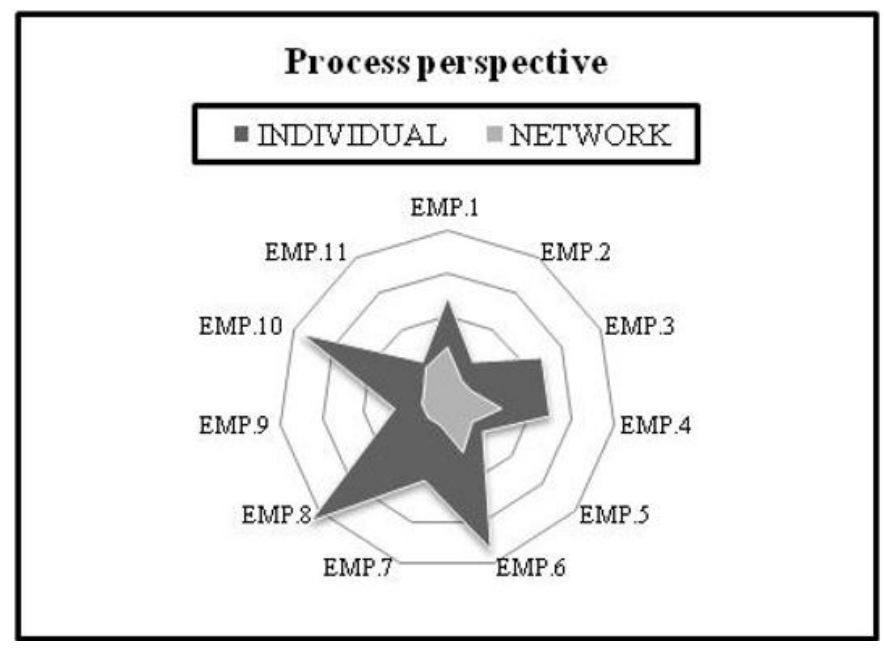

Figure 9. Individual and network management for the Process perspective. EMP.1: Company 1; EMP.2: Company 2; EMP.3: Company 3; EMP.4: Company 4; EMP.5: Company 5; EMP.6: Company 6; EMP.7: Company 7; EMP.8: Company 8; EMP.9: Company 9; EMP.10: Company 10; EMP.11: Company 11. 
In regard to the release of indicators from the process perspective, we concluded that companies most often do not share their indicators with the other companies; however, they do share indicators with some specific partners informally. The explanation is that the information they have is irrelevant to the other companies in the network. However, some information and indicators about the companie's processes are exchanged sporadically with other trusted partners.

In regard to the growth/learning perspective, Figure 10 shows that only companies 3, 4, and 10 have and use formal performance indicators to evaluate factors such as the anticipation of market changes, innovative products, and coaching and/or lectures for professional development. The remaining companies use indicators to measure such factors, but do it informally.

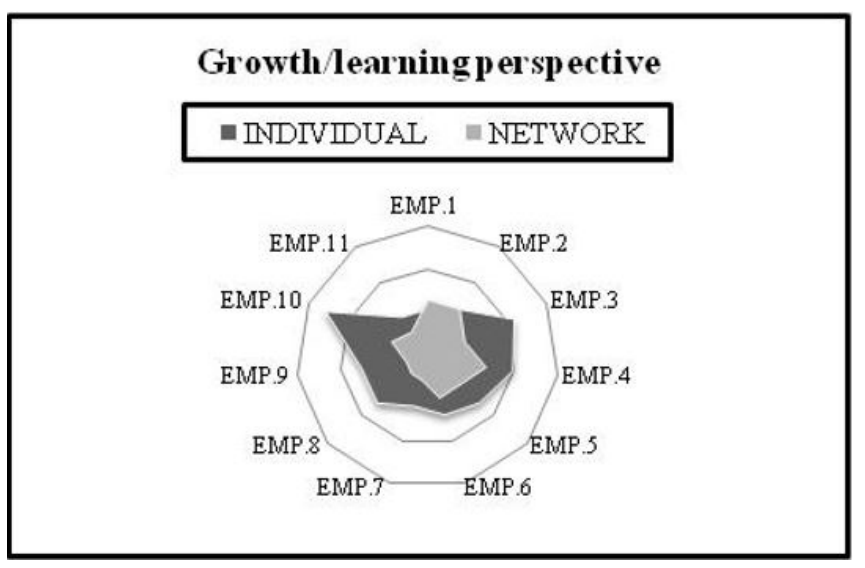

Figure 10. Individual and network management for the Growth/Learning perspective. EMP.1: Company 1; EMP.2: Company 2; EMP.3: Company 3; EMP.4: Company 4; EMP.5: Company 5; EMP.6: Company 6; EMP.7: Company 7; EMP.8: Company 8; EMP.9: Company 9; EMP.10: Company 10; EMP.11: Company 11.

Regarding to the sharing of these indicators among the network's actors, it is observed that it is almost null and, if it occurs, is just done occasionally between reliable partners.

The exchange of indicators relating to the growth/learning factors is limited because there are no formal indicators to evaluate this perspective.

Figure 11 shows the graph that demonstrates the individual and joint use of indicators by companies for the collaboration perspective.

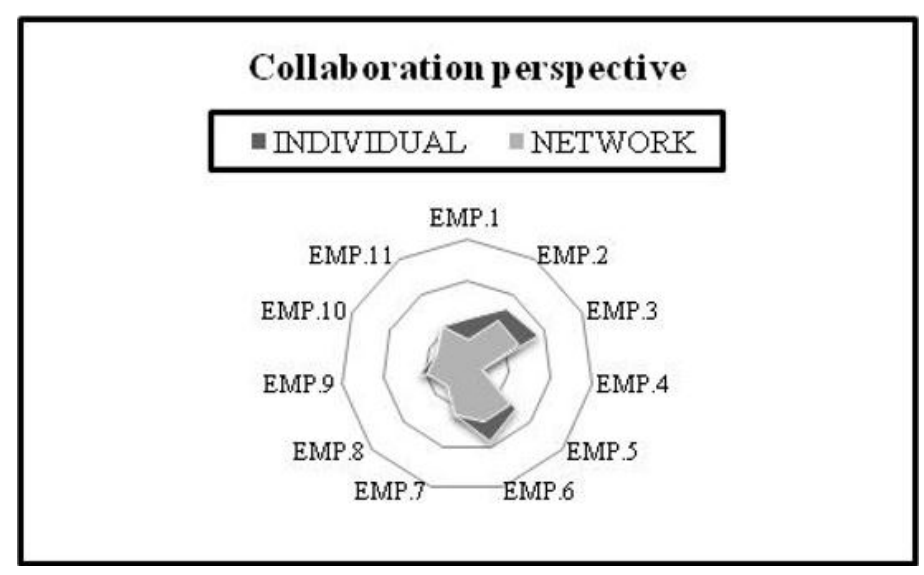

Figure 11. Individual and network management for the collaboration perspective. EMP.1: Company 1; EMP.2: Company 2; EMP.3: Company 3; EMP.4: Company 4; EMP.5: Company 5; EMP.6: Company 6; EMP.7: Company 7; EMP.8: Company 8; EMP.9: Company 9; EMP.10: Company 10; EMP.11: Company 11. 
For the collaboration perspective, there were no formal indicators to evaluate the following factors: collaborative meetings between partners, health of the collaboration index, collaboration practices between partner, and quantity and quality of the information shared. It was clear that, except for the number of collaborative meetings between partners, the other factors represent qualitative factors, which are more challenging to measure.

The evaluation is informal in regard to factors such as reliable partners, number of events, coaching, and courses in which there is joint participation, and sharing results with other companies. These translate into cost of registrations and company marketing at events, interest of professionals and contact with companies from the same sector. It is also evident that information is shared in an informal way among the partners, and enterprises do not use indicators to evaluate collaboration among the actors of the network.

\section{Conclusion}

The development of the model for the analysis of performance management in the horizontal networks of companies proposed in this work contributes to existing literature, suggests methods for managers of enterprises and pointers for further research.

\subsection{Theoretical contribution}

The proposed model meets its initial objective of identifying the perspectives and performance factors that guide the management of horizontal networks of companies, in addition to helping companies measure them. Past studies only cited factors in the performance sphere; however, there was a grace period for the measurement of these factors both at the level of company's management and at the network level. The developed model contributes a set of eight perspectives and 25 performance factors, which measure performance by means of weighting of perspectives, diagnosis of the factors and equations proposed by the model. With the measurement of the perspectives and factors, it becomes possible to create a diagram that gives a diagnosis of company and network management.

\subsection{Management contribution}

The proposed model informs managers of companies about the level of development, both enterprises and the network. Using the diagnostic procedure, managers can manage the companies that most collaborate to the development of the network. Another strong feature of the model is that it allows the individual analysis of the evaluation perspectives, which makes possible a benchmarking of the participants, in addition to highlighting the perspectives most lacking insuitable indicators for measuring performance.

The model is also flexible, being applicable to companies in sectors such as information technology services, metallurgy, and furniture, among others. The perspectives and factors not applicable to a sector can be excluded and more importance for the sector tend to obtain a larger weight.

\subsection{Limitations and future research}

A suggestion to ensure the continuity of this survey is to assess the potential for inclusion of other performance factors. It is still possible to continue the development of the model proposing suitable indicators for each of the factors proposed in the model, which would lead to a standardization of results and a more accurate comparison of the performance of companies.

\section{References}

Beugelsdijk, S., McCann, P., \& Mudambi, R. (2010). Introduction: place, space and organization - economic geography and the multinational enterprise. Journal of Economic Geography, 10(4), 485-493. http://dx.doi.org/10.1093/jeg/lbq018.

Coleman, J. S. (1988). Social capital in the creation of human capital. American Journal of Sociology, 94, 95-120. http://dx.doi. org/10.1086/228943.

Delgado, M., Porter, M. E., \& Stern, S. (2010). Clusters and entrepreneurship. Journal of Economic Geography, 10(4), 495-518. http:// dx.doi.org/10.1093/jeg/lbq010.

Diez-Vial, 1. (2011). Geographical cluster and performance: the case of lberian ham. Food Policy, 36(4), 517-525. http://dx.doi. org/10.1016/j.foodpol.2011.04.002.

Ferreira, P. S., Cunha, P. F., Carneiro, L., \& Sá, A. (2011a). An approach to performance management in collaborative networks based on stakeholders' key success factors. In: L.M. Camarinha-Matos, A. Pereira-Klen, \& H. Afsarmanesh (Eds), Adaptation and value 
creating collaborative networks - PRO-VE 2011 IFIP advances in information and communication technology (Vol. 362, pp. 140147). Heidelberg: Springer. https://doi.org/10.1007/978-3-642-23330-2_16.

Ferreira, R. P., Silva, J. N., Strauhs, F. R., \& Soares, A. L. (2011b). Performance management in collaborative networks: a methodological proposal. Journal of Universal Computer Science, 17(10), 1412-1429.

Ferreira, R. P., \& Soares, A. L. (2010). A collaborative decision support method to design performance evaluation systems in CNOs. In: L.M. Camarinha-Matos, X. Boucher, \& H. Afsarmanesh (Eds), Collaborative networks for a sustainable world - PRO-VE 2010 IFIP advances in information and communication technology (Vol. 336, pp. 561-568). Heidelberg: Springer. https://doi.org/10.1007/9783-642-15961-9_67.

Francisco, R. P., \& Azevedo, A. (2009). An SSM-Based approach to implement a dynamic performance management system. In: L.M. Camarinha-Matos, l. Paraskakis, \& H. Afsarmanesh (Eds), Leveraging knowledge for innovation in collaborative networks - PROVE 2009 IFIP Advances in information and communication technology (Vol. 307, pp. 476-483). Heidelberg: Springer. https://doi. org/10.1007/978-3-642-04568-4_49.

Francisco, R. P., Azevedo, A., Bastos, J., \& Almeida, A. (2011). Using key alignment indicators for performance evaluation in collaborative networks. In: L.M. Camarinha-Matos, A. Pereira-Klen, \& H. Afsarmanesh (Eds), Adaptation and value creating collaborative networks - PRO-VE 2011 IFIP advances in information and communication technology (Vol. 362, pp. 159-166). Heidelberg: Springer. https:// doi.org/10.1007/978-3-642-23330-2_18.

Francisco, R. P., Azevedo, A., \& Almeida, A. (2012). Alignment prediction in collaborative networks. Journal of Manufacturing Technology Management, 23(8), 1038-1056. http://dx.doi.org/10.1108/17410381211276862.

Francisco, R. P., Azevedo, A., \& Bastos, J. (2010). Managing performance to align the participants of collaborative networks: case studies results. In: L.M. Camarinha-Matos, X. Boucher, \& H. Afsarmanesh (Eds), Collaborative Networks for a Sustainable World - PRO-VE 2010 IFIP Advances in Information and Communication Technology (Vol. 336, pp. 545-552). Heidelberg: Springer. https://doi. org/10.1007/978-3-642-15961-9_65.

Galdámez, E. V. C., Carpinetti, L. C. R., \& Gerolamo, M. C. (2009). Proposta de um sistema de avaliação do desempenho para arranjos produtivos locais. Revista Gestão \& Produção, 16(1), 133-151.

Jofre-Monseny, J. (2009). The scope of agglomeration economies: evidence from Catalonia. Papers in Regional Science, 88(3), 575-590. http://dx.doi.org/10.1111/j.1435-5957.2009.00226.x.

Kaplan, R. S., \& Norton, N. (1992). The balanced scorecard: measures that drive performance. Harvard Business Review, 70(1), 71-79. PMid:10119714.

Libaers, D., \& Meyer, M. (2011). Highly innovative small technology firms, industrial clusters and firm internationalization. Research Policy, 4O(10), 1426-1437. http://dx.doi.org/10.1016/j.respol.2011.06.005.

Lima, R. H. P., Guerrini, F. M., \& Carpinetti, L. C. R. (2011). Performance measurement in collaborative networks: a proposal of performance indicators for the manufacturing industry. International Journal of Business Excellence, 4(1), 61-79. http://dx.doi. org/10.1504/1JBEX.2011.037249.

Neves, M. P. S., Diehl, C. A., Hansen, P. B., \& Becker, G. V. (2011). Análise do processo de coopetição em redes horizontais de pequenas e médias empresas do Rio Grande do Sul. BASE: Revista de Administração e Contabilidade da Unisinos, 8(3), 243-260.

Pagani, R. N., Kovaleski, J. L., \& Resende, L. M. (2015). Methodi Ordinatio: a proposed methodology to select and rank relevant scientific papers encompassing the impact factor, number of citation, and year of publication. Scientometrics, 105(3), 2109-2135. http:// dx.doi.org/10.1007/s11192-015-1744-x.

Pekkola, S. (2013). Managing a network by utilizing performance measurement information. Measuring Business Excellence, 17(1), 72-79. http://dx.doi.org/10.1108/13683041311311374.

Potter, A., \& Watts, H. D. (2010). Evolutionary agglomeration theory: increasing returns, diminishing returns, and the industry life cycle. Journal of Economic Geography, 11(3), 417-455. http://dx.doi.org/10.1093/jeg/lbq004.

Saaty, T. L. (1990). How to make a decision: the analytic hierarchy process. European Journal of operational Research, 48, 9-26.

Saiz, J. J. A., Bas, A. O., \& Rodríguez, R. R. (2007). Performance measurement system for enterprise networks. International Journal of Productivity and Performance Management, 56(4), 305-334. http://dx.doi.org/10.1108/17410400710745324.

Verdecho, M. J., Alfaro-Saiz, J. J., Rodríguez, R. R., \& Bas, O. A. (2012). Retracted: the analytic network process for managing interenterprise collaboration - a case study in a collaborative enterprise network. Expert Systems with Applications, 39(1), 626-637. http://dx.doi.org/10.1016/j.eswa.2011.07.054.

Verdecho, M. J., Rodríguez, R. R., \& Saiz, J. J. A. (2011). A Structured methodology to implement performance measurement systems in collaborative networks. In: L.M. Camarinha-Matos, A. Pereira-Klen, \& H. Afsarmanesh (Eds), Adaptation and value creating collaborative networks - PRO-VE 2011 IFIP advances in information and communication technology (Vol. 362, pp. 151-158). Heidelberg: Springer. https://doi.org/10.1007/978-3-642-23330-2_17.

Verdecho, M. J., Saiz, J. J. A., \& Rodríguez, R. R. (2010). An approach to select suppliers for sustainable collaborative networks. ln: L.M. Camarinha-Matos, X. Boucher, \& H. Afsarmanesh (Eds), Collaborative networks for a sustainable world. PRO-VE 2010 IFIP advances in information and communication technology (Vol. 336, pp. 304-311). Heidelberg: Springer. https://doi.org/10.1007/9783-642-15961-9_36.

Wang, H., Peverelli, P. J., \& Bossink, B. A. G. (2014). The development of asymmetric trust in cooperation between large firms and smes: insights from china. Group Decision and Negotiation, 24(5), 925-947. http://dx.doi.org/10.1007/s10726-014-9422-6.

Wegner, D, \& Ribeiro, JLD (2011). Avaliação de desempenho de redes horizontais de empresas: um estudo exploratório. Revista Alcance, 18(1), 59-74.

Wegner, D., Alievi, R. M., Begnis, H. S. M., \& Maehler, A. E. (2013). The dynamics of cooperation: proposal of a small-firms networks life cycle model. In Proceedings of the 15th International Academy of Management and Business Conference, Lisboa.

Wu, W. Y., Shih, H. S., \& Chan, H. C. (2009). The analytic network process for partner selection criteria in strategic alliances. Expert Systems with Applications, 36(3), 4646-4653. http://dx.doi.org/10.1016/j.eswa.2008.06.049.

Xu, Y. L., Wang, Q., \& Wang, W. (2011, 9-11, September). Fuyang paper industrial cluster performance evaluation based on fuzzy evaluation. In Electronics, Communications and Control (ICECC), International Conference (pp. 3198-3200), Ningbo, China: IEEE. http://dx.doi.org/10.1109/1CECC.2011.6068142. 